Artigo

\title{
Programas de orientação sexual nas escolas: uma análise das lacunas na implementação de políticas públicas a partir da percepção dos alunos da rede municipal de ensino de São Paulo
}

\begin{abstract}
Sexual orientation programs in schools: an analysis of gaps in the implementation of the public policies based on the students' perception of the city of São Paulo

Programas de orientación sexual en las escuelas: un análisis de las deficiencias en la aplicación de políticas públicas desde la percepción de los estudiantes da cidade de São Paulo
\end{abstract}

Kátia Cibelle Machado Pirotta ${ }^{1}$, Renato Barboza², Lígia Rivero Pupo ${ }^{3}$, Sandra Unbehaum ${ }^{4}$, Sylvia Cavasin ${ }^{5}$.

\footnotetext{
${ }^{1}$ Filiação institucional. Cientista Social, Doutora em Saúde Pública pela Universidade de São Paulo, Pesquisadora Científica V do Instituto de Saúde.

Correspondência: E-mail: katiapirotta@hotmail.com

${ }^{2}$ Filiação institucional. Cientista Social, Mestre em Saúde Coletiva pela Coordenadoria de Controle de Doenças/SES-SP, Pesquisador Científico V do Instituto de Saúde e pesquisador do NEPAIDS da Universidade de São Paulo.

Correspondência: $\quad$ E-mail: renato@isaude.sp.gov.br

${ }^{3}$ Filiação institucional. Psicóloga, Mestre em Medicina Preventiva pela Universidade de São Paulo, Pesquisadora Científica IV do Instituto de Saúde.

Correspondência: $\quad$ E-mail: ligia@isaude.sp.gov.br

4 Filiação institucional. Cientista Social, Doutora em Educação pela Pontifícia Universidade Católica de São Paulo, Pesquisadora e Coordenadora do Departamento de Pesquisas Educacionais da Fundação Carlos Chagas.

Correspondência: E-mail: unbehaum@hotmail.com

${ }^{5}$ Filiação institucional. Cientista Social, Pesquisadora e Diretora da Organização Não Governamental Ecos - Comunicação em Sexualidade.

Correspondência: $\quad$ E-mail: sylviacavasin@uol.com.br
} 
Resumo

No plano normativo e teórico, o papel das escolas na orientação sexual e a sua importância para construção da autonomia e do projeto de vida de crianças e adolescentes é incontroverso. Apesar disso, prevalece o tratamento dessas questões sob uma ótica repressora, focada na ideia de risco e na prevenção das doenças sexualmente transmissíveis e da gravidez. Este artigo teve por objetivo analisar a percepção de alunos sobre os programas de orientação sexual realizados na rede municipal de ensino de São Paulo. Os dados integram o projeto "Educação Sexual na Escola e Direitos Sexuais e Reprodutivos - Avaliação da Política da Secretaria Municipal de Educação de São Paulo 2001 a 2005". Como parte desse projeto foi feito um levantamento descritivo, de caráter exploratório, com 341 entrevistados, sorteados em oito escolas municipais, no ano de 2006. Os resultados indicaram a realização de ações pontuais e informativas, nas aulas de ciências e em palestras com profissionais de saúde. Não se observou a realização de um trabalho processual, interdisciplinar e intersetorial. Os temas abordados foram a contracepção, as doenças sexualmente transmissíveis, o HIV/Aids, a gravidez e as drogas. Nota-se um pequeno envolvimento de pais e familiares. Mais de um terço dos estudantes referiu não ter participado de nenhuma ação na área da orientação sexual. Conclui-se que prevalece uma concepção descontextualizada da sexualidade e da promoção da saúde. São oferecidas respostas prontas, indicando que os professores não se sentem respaldados para utilizar uma metodologia construtivista. A visão dos alunos reproduz essa lógica, o que pode leva-los a adotar posturas pouco responsáveis e discriminatórias em relação à sua vida e saúde. Transformar uma plataforma de orientação sexual em uma política pública efetiva permanece um grande desafio para a escola e para a sociedade.

Palavras-chaves: Políticas Públicas, Educação Sexual, Desenvolvimento de Programas, Adolescente, Programas Governamentais. 
Abstract

In the normative and theoretical level, the role of schools on sexual orientation and its importance for the construction of autonomy and the children and adolescents' life project is incontrovertible. Nevertheless, prevails consideration of these issues under a repressive perspective, focused on the idea of risk and prevention of sexually transmitted diseases and pregnancy. This article aimed to analyze the students' perception on sex education programs carried out in the teaching system of the city of São Paulo. The data are part of the project "Sexual Education in School and Sexual and Reproductive Rights - Policy Evaluation of the Municipal Department of Education of São Paulo from 2001 to 2005". As part of this project, was made a descriptive research, exploratory, with 341 respondents, drawn in eight public schools, in 2006. As part of this project we conducted a descriptive research, exploratory, with 341 respondents, drawn in eight public schools, in 2006. The results indicated the achievement of specific and informative actions, in science classes and lectures with health professionals. There was not the realization of a procedural, interdisciplinary and intersectoral work. Topics covered included contraception, sexually transmitted diseases, HIV/AIDS, pregnancy and drugs. It was noted a small involvement of parents and family. More than a third of students reported not having participated in any action in the area of sexual orientation.It follows that prevails a decontextualized vision about the sexuality and health promotion. Ready answers are offered, indicating that teachers do not feel supported to use a constructivist methodology. The students' vision plays this logic, which may lead them to adopt little responsible and discriminatory attitudes with the life and the health. Turning a sexual orientation platform in an effective public policy remains a major challenge for the school and society.

Keywords: Public Policies, Sex Education, Program Development, Adolescent, Government Programs. 
Resumen En el plano normativo y teórico, el papel de la escuela en la orientación sexual y su importancia para la construcción de la autonomía y del proyecto de vida de los niños y adolescentes es incontrovertible. Sin embargo, la consideración predominante de estos temas en una perspectiva represiva, se centró en la idea del riesgo y la prevención de enfermedades de transmisión sexual y el embarazo. Este artículo tuve como objetivo analizar la percepción de los estudiantes sobre los programas de orientación sexual desarrollados en la ciudad de São Paulo. Los datos forman parte del proyecto "Educación Sexual en la Escuela y los Derechos Sexuales y Reproductivos - Evaluación de Políticas de la Secretaría Municipal de Educación de São Paulo desde 2001 hasta 2005". Como parte de este proyecto se realizó una investigación descriptiva, exploratoria, con 341 encuestados, elegidos en ocho escuelas públicas, en el año 2006. Los resultados indicaron la realización de acciones pontuales y informativas, en las clases de ciencias y ponencias a cargo de profesionales de salud. No se llevo a cabo un labor procesual, interdisciplinario y intersectorial. Los temas cubiertos incluyen la anticoncepción, enfermedades de transmisión sexual, el VIH/SIDA, el embarazo y las drogas. Hubo una pequeña participación de los padres y familiares. Más de un tercio de los estudiantes reportaron no participar en cualquier acción en el ámbito de la orientación sexual. Se resulta que aun prevalece una concepción descontextualizada de la sexualidad y promoción de salud. Respuestas listas se ofrecen, lo que indica que los profesores no se sienten apoyados para utilizar una metodología constructivista. La visión de los estudiantes, reproduce esta lógica, lo que puede llevar a adoptar actitudes poco responsables y discriminatorias con su vida y la salud. Convertir una plataforma de orientación sexual en una política pública eficaz sigue siendo un gran desafío para la escuela y la sociedad.

Palabras Clave: Políticas Públicas, Educación Sexual, Desarrollo de Programa, Adolescente, Programas de Gobierno. 


\section{Introdução}

No Brasil, as políticas públicas no campo da educação sexual remontam à década de 60, quando aconteceram as primeiras experiências no país. Nas primeiras décadas do século $X X$, é possível encontrar a preocupação com o tema, sobretudo devido ao medo das doenças 'venéreas', no entanto as ações possuíam um caráter repressivo em relação à sexualidade. Na década de 60, ocorreram as primeiras experiências formais e sistematizadas nas escolas, as quais foram suspensas após o golpe militar. Em 1971, a Lei 5.692, que instituiu o ensino de $1^{\circ}$ e $2^{\circ}$ graus, torna obrigatória a inclusão de programas de saúde no curriculum escolar. Posteriormente, o Conselho Federal de Educação recomendou que os programas fossem planejados de acordo com as necessidades do meio e dos alunos (Silva e Megid Neto, 2006; Arilha e Calazans, 1998).

Na saúde, a sexualidade volta ao debate nos anos 70, através da influência das reivindicações do movimento feminista. A implementação de programas na área de saúde da mulher teve seu marco na década de 80 com o Programa de Assistência Integral a Saúde da Mulher (PAISM). Nessa mesma época, iniciou-se o Programa Nacional de DST/AIDS, além do Programa de Saúde do Adolescente (PROSAD), embora esse último não tenha sido implementado de fato. (Galvão \& Díaz, 1999)

Com a Conferência Internacional sobre População e Desenvolvimento, realizada no Cairo, em 1994 (Nações Unidas, 1994), e a Quarta Conferência Mundial sobre a Mulher, Desenvolvimento e Paz, ocorrida logo em seguida, em Beijing, no ano de 1995 (United Nations, 1995), constituem-se os marcos fundamentais para uma mudança no tratamento dado à sexualidade e à reprodução. São reconhecidos os direitos sexuais e os direitos reprodutivos, que integram os Direitos Humanos, além de serem estabelecidos os princípios que os norteiam. A partir do advento das Conferências, os países signatários comprometem-se a adotar suas definições, princípios e recomendações para promover políticas públicas e adequar as legislações no âmbito de seus sistemas jurídicos internos. 
Esses documentos enfatizam a necessidade de implementar programas de orientação sexual e de saúde sexual e reprodutiva voltados para a população de adolescentes e jovens. O acesso a programas intersetoriais sobretudo aqueles que envolvem educação e saúde - é tomado como elemento fundamental para que a população jovem vivencie a sua sexualidade de forma mais plena e saudável e para uma mudança nas dinâmicas de gênero em toda a sociedade.

Destaca-se o 40ํ Princípio da Plataforma de Ação de Beijing, segundo o qual os gestores dos programas e das políticas públicas devem tomar medidas especiais que promovam as condições para que os jovens, e especialmente as mulheres, tenham uma participação ativa e efetiva em todos os níveis de liderança social, cultural, política e econômica. Destaca-se no texto que

Metade da população mundial tem menos de 25 anos de idade e a maioria dos jovens no mundo (+ de 85\%) vive em países em desenvolvimento. Os gestores de políticas devem reconhecer as implicações desses fatores demográficos. Medidas especiais devem ser tomadas para assegurar que as mulheres jovens tenham as condições de vida necessárias para uma participação ativa e efetiva em todos os níveis de liderança social, cultural, política e econômica. Será crucial para a comunidade internacional demonstrar um novo compromisso com o futuro - um compromisso de inspirar uma nova geração de mulheres e homens a trabalharem juntos por uma sociedade mais justa. Esta nova geração de líderes deve aceitar e promover um mundo no qual toda a criança seja livre da injustiça, da opressão e da desigualdade e livre para desenvolver seu próprio potencial. O princípio da igualdade de mulheres e homens deve, finalmente, ser integral no processo de socialização. (United Nations, 1995)

No plano jurídico nacional, o Artigo 227 da Constituição Federal de 1988 define a responsabilidade e o dever do Estado, da família e da sociedade quanto à proteção integral da criança e do adolescente. Posteriormente, em 1990, na Convenção Internacional dos Direitos da Criança nas Nações Unidas, o Brasil assumiu o compromisso de promover mecanismos e instrumentos capazes de assegurar direitos, promulgando no mesmo ano a Lei 8.069/1990, que dispõe sobre o Estatuto da Criança e do Adolescente (ECA), e institui o Conselho Nacional dos Direitos da Criança e do Adolescente (CONANDA). No âmbito regional, cabe destacar a criação dos Conselhos Estaduais e dos Conselhos Tutelares nos municípios brasileiros.

A Constituição de 1988 e a aprovação do ECA são marcos em relação à defesa dos direitos das crianças e dos adolescentes na construção de uma 
sociedade democrática. No entanto, no tocante às questões relacionadas à sexualidade, o ECA não inova afirmando direitos em relação à sexualidade e à vida reprodutiva. A invisibilidade da sexualidade dos jovens acaba tendo por consequência o aumento da vulnerabilidade desse grupo em relação à saúde sexual e reprodutiva. (Pirotta \& Pirotta, 1999; 2005)

Observa-se um incremento nas políticas públicas para os jovens nos anos 90. O foco das ações concentra-se nas ações para o combate da violência urbana, o desemprego, a prostituição infantil, a violência doméstica e sexual. A partir do campo da saúde, a vida reprodutiva e as práticas sexuais dos adolescentes são problematizadas como, por exemplo, o debate sobre a gravidez na adolescência, o aborto, a vulnerabilidade ao HIV/AIDS e às doenças sexualmente transmissíveis (DST). Apesar dos avanços encontrados, prevalece um tratamento das questões relacionadas à população jovem sob a ótica do desvio ou do problema social.

No âmbito da educação, os principais documentos vigentes nas últimas duas décadas no país são: a Nova Lei de Diretrizes e Bases da Educação Nacional (LDB) de 1996 (Lei № 9.394/1996), a qual redefiniu o escopo e os eixos programáticos das políticas públicas para a educação; os Parâmetros Curriculares Nacionais (PCN), de 1997, que trouxeram inovações significativas na abordagem dos temas pedagógicos e na estrutura curricular; e o Plano Nacional de Educação de 2001 (Lei № 10.172/2001) que estabeleceu as metas nacionais sob a gestão do Ministério da Educação em estreita articulação com as Secretarias Estaduais e Municipais.

Um dos desdobramentos mais relevantes da LDB diz respeito à publicação dos PCN, os quais forneceram subsídios e diretrizes técnicas para a elaboração e a revisão da estrutura curricular adotada pelas Secretarias Estaduais e Municipais de Educação. O diferencial desse documento norteador refere-se às ações pedagógicas, apoiadas em Temas Transversais, os quais abordam um conjunto de assuntos que devem ser discutidos de forma interdisciplinar com vistas à formação de sujeitos críticos e conscientes dos seus direitos e deveres sociais. Dessa forma, os temas ética, meio ambiente, pluralismo cultural, consumo, saúde e orientação sexual estão ancorados na perspectiva da educação para a cidadania, a qual implica a sensibilização e a participação ativa de todos os segmentos da comunidade escolar (Ministério da Educação e do Desporto, 1997).

Os PCNs (...) apresentam como maior inovação a inclusão de temas que visam a resgatar a dignidade da pessoa humana, a igualdade de direitos, $\mathrm{o}$ cuidado de si e dos outros, a participação ativa na sociedade e a coresponsabilidade pela vida social. O documento adota como eixo 


\begin{abstract}
norteador o desenvolvimento de capacidades de alunas e alunos, processo esse em que os conteúdos curriculares devem atuar como meios para aquisição e desenvolvimento dessas capacidades, e não como fins em si mesmos. Não se trata de negar a importância do acesso ao conhecimento socialmente acumulado pela humanidade, mas sim de incluir na pauta educacional temas relacionados diretamente ao exercício da cidadania. (Vianna \& Unbehaum, 2004, p.96)
\end{abstract}

Por tratar-se de um campo multidisciplinar, ou seja, para o qual concorrem conhecimentos de diferentes áreas do saber, e considerando-se a adolescência na sua integralidade, preconiza-se o desenvolvimento de ações intersetoriais, sobretudo nas questões atinentes à saúde sexual e reprodutiva. (Ministério da Saúde, 2005) Ações intersetoriais requerem um processo institucional capaz de promover a articulação de saberes e experiências para a realização de objetivos comuns. Essas ações implicam na identificação de parceiros, convergências de responsabilidades, compartilhamento do poder, associação de interesses, saberes e práticas. (Inojosa, 1998). Destaca-se a importância das parcerias entre os setores da Saúde e da Educação para um tratamento integral ao adolescente e ao jovem.

Nessa ótica, preconiza-se que saúde e orientação sexual devem ser trabalhados pelas escolas desde o primeiro ciclo e ao longo do processo da educação formal dos alunos, adotando-se atividades pedagógicas internas e externas à sala de aula e envolvendo além dos educadores, outros profissionais, sobretudo aqueles que atuam na área da saúde, nas organizações não governamentais, nos conselhos e em outros setores afins, evidenciando assim, a relevância das parcerias no processo de promoção da saúde e desenvolvimento da sexualidade das crianças e dos adolescentes.

Os especialistas no tema reconhecem a relevância dos PCN na definição de diretrizes técnicas que embasam a discussão das temáticas de gênero e sexualidade, contudo demonstram que ainda há lacunas e fragilidades teóricas que dificultam a sua adoção no sistema educacional e nas escolas (Altmann, 2001; Junqueira, 2009).

Estudiosos como Helena Altmann, através da análise dos documentos oficiais, constatam que os PCN apresentam a sexualidade como um dado da natureza, inerente e necessário à vida. Na análise realizada por Helena Altmann (2001), “A sexualidade e o sujeito são pensados como essências sob as quais há um investimento da cultura" (p. 581). A orientação sexual é entendida como sendo de caráter informativo e, mesmo admitindo diferentes manifestações da sexualidade, o documento não problematiza a categoria "sexualidade". Apoiando-se nos estudos de Foucault, a autora conclui que: "Através da colocação do sexo em discurso, parece haver um complexo aumento de 
controle sobre os indivíduos, o qual se exerce não tanto através de proibições e punições, mas através de mecanismos, metodologias e práticas que visam a produzir sujeitos autodisciplinados no que se refere à maneira de viver sua sexualidade" (p. 584)

A atual preocupação com a orientação sexual na escola está vinculada à gravidez na adolescência e à epidemia de Aids, surgida no Brasil durante os anos 80. O levantamento bibliográfico realizado por Regina C. P. da Silva e Jorge Megid Neto (2006) aponta que parte expressiva da produção científica sobre a formação de educadores para a orientação sexual ainda tem o foco em doenças sexualmente transmissíveis e Aids. Predomina o discurso do medo e da doença, cujo enfoque é de cunho biologicista e higienista. A preocupação centra-se na transmissão de informações ou no controle e cerceamento da sexualidade dos jovens. As crianças menores são excluídas das ações de prevenção, dado que a imagem da Aids é incompatível com a visão de que a criança é pura e destituída de sexualidade. Os autores observam que: "Relatos de posturas indicam que os professores/educadores não conseguem lidar com a sexualidade infantil, tem dificuldades com o homossexualismo e as relações de gênero e tendem a abordar a educação sexual de forma desigual para ambos os sexos..." (p.193). A noção de sexualidade presente na escola e a tematização das doenças sexualmente transmissíveis, da Aids e da gravidez adolescente, somadas a um discurso em torno da responsabilização dos sujeitos, afastam as oportunidades de um debate mais crítico, plural e inovador com as crianças e os adolescentes (Louro, 2004).

Um estudo realizado por Dulcilene P. Jardim e José Roberto da S. Brêtas (2006) com professores averiguou que $45 \%$ dos entrevistados consideravam que os pais são os maiores responsáveis pela tarefa de orientar sobre a sexualidade. $21 \%$ dos professores responderam não saber como abordar os assuntos com os estudantes. Perguntados quanto aos assuntos que deveriam ser abordados na escola, 38\% responderam que deve ser falado apenas sobre gravidez na adolescência e métodos contraceptivos e $30 \%$ responderam que as doenças sexualmente transmissíveis e sua prevenção devem ser mencionadas.

No estudo acima citado, somente um terço dos professores entrevistados responderam sentir-se seguro para conversar sobre a sexualidade com os alunos. Regina C. P. da Silva e Jorge Megid Neto (2006) afirmam que esse despreparo produz condutas discriminatórias e pouco reflexivas: "Como o tema da sexualidade em sala de aula desperta medo, sentimentos de despreparo, vergonha, insegurança e falta de confiança, as ações dos profissionais acabam norteadas pelos valores pessoais dos mesmos, o que está diretamente relacionado aos limites e às dificuldades constatadas nas pesquisas e que contribuem para obstaculizar a implantação da educação sexual nas escolas" (p. 192). 
Weeks (1999), citado por Junqueira (2009:183), é enfático ao mencionar que: "Aqui, limito-me a notar que, vista a partir da tônica da prevenção de doenças e não da promoção de uma cultura dos direitos (na qual estariam incluídos os direitos sexuais, entendidos de maneira plural e em favor da autonomia dos sujeitos), a sexualidade poderá permanecer no plano do risco e da ameaça. Em tais circunstâncias, os discursos e as práticas tenderão a reverberar e a alentar as mobilizações conservadoras que, desde os anos 1970 nos Estados Unidos e na Europa, vêm preconizando uma política sexual voltada a conter as "ameaças à família" e à normalidade heterossexual (Weeks, 1999, p.76-77)."

Diante do quadro traçado acima, o estudo "Educação Sexual na Escola e Direitos Sexuais e Reprodutivos - Avaliação da Política da Secretaria Municipal de Educação de São Paulo 2001 a 2005", financiado pelo Programa de Apoio a Projetos em Sexualidade e Saúde Reprodutiva (PROSARE), visou conhecer como a plataforma dos direitos sexuais e direitos reprodutivos é colocada em movimento em nossa sociedade e como esse marco é incorporado em ações concretas na área da orientação sexual na rede municipal de ensino de São Paulo. Para tanto, foi realizado um estudo de três dos principais projetos relativos à orientação sexual, implementados pela Secretaria Municipal de Educação de São Paulo, entre os anos de 2001 e 2005: "Programa de Educação Preventiva e Sexualidade", desenvolvido entre 2001 e 2003, em parceria entre as Secretarias Municipais de Educação e da Saúde; o "Projeto Orientação Sexual na escola: um trabalho processual", uma parceria entre a Secretaria Municipal de Educação e uma Organização Não Governamental, no biênio 2003-2004; e o projeto "Vamos Combinar?", desenvolvido em parceria pelas Secretarias Municipais de Educação e da Saúde, iniciado em 2003 e estendendo-se até 2005. (Pirotta et al., 2006)

\section{Objetivo}

Em relação ao seu marco conceitual, os três projetos analisados apresentam concepções que estão de acordo com os princípios mais modernos e democráticos em relação ao tratamento da sexualidade e aos direitos sexuais e direitos reprodutivos, em consonância com as plataformas internacionais e com as diretrizes mais recentes para as políticas públicas "de" juventude - as quais pressupõem o reconhecimento dos adolescentes e jovens como sujeitos de direitos e o respeito à sua autonomia, integridade e intimidade.

O presente trabalho teve por objetivo averiguar, a partir da percepção dos alunos, os resultados dos programas e dos projetos de orientação sexual 
realizados na rede pública municipal de ensino de São Paulo, no período de 2001 a 2005.

\section{Metodologia}

Em 2006, a Secretaria Municipal de Educação de São Paulo era formada por uma rede de 1.839 equipamentos com capacidade instalada para oferecer 1.184.585 vagas públicas, gerenciadas de forma descentralizada por meio de 13 Coordenadorias de Educação. Na época do estudo, o universo dos equipamentos de ensino médio municipal era constituído por oito escolas, que também ofereciam o ensino fundamental. A opção metodológica por realizar a pesquisa nessas escolas deve-se a que muitos dos alunos vinham do ensino fundamental onde haviam participado das ações de orientação sexual, o que permitiu reconstituir um retrato das atividades pedagógicas vivenciadas pelos alunos durante sua formação nos últimos anos.

Nas oito escolas que participaram do estudo, foram encontradas 85 salas de aula com 2.967 alunos matriculados. Optou-se pela realização de uma amostra representativa do universo pesquisado, baseada na técnica de amostragem por conglomerados (Levin, 1987; Fonseca \& Martins, 1996). O tamanho da amostra foi dimensionado em 340 alunos. Tendo em vista a evasão dos alunos, a perda foi estimada em 27\%. Foram sorteadas 14 salas com um total de 431 alunos matriculados. Em cada sala sorteada, foram entrevistados todos os alunos matriculados que estavam cursando regularmente o ensino médio. A equipe de pesquisa retornou até três vezes nas salas sorteadas para entrevistar os alunos que não estivessem presentes nas visitas anteriores. Ao final, 341 estudantes sorteados responderam a um questionário autoaplicado, pré-testado anteriormente.

Os questionários foram aplicados em todas as turmas dos primeiros e terceiros anos do ensino médio nos períodos matutino, vespertino e noturno para mensurar, retrospectivamente, o quanto os alunos participaram de atividades pedagógicas relacionadas à orientação sexual, à saúde reprodutiva e aos direitos sexuais e reprodutivos, bem como sua opinião a respeito destas atividades e a importância das mesmas para a sua vida. Os dados coletados foram tabulados e organizados em planilha Excel e submetidos à análise descritiva baseada em frequências absolutas e relativas. O presente estudo possui caráter descritivo e exploratório. 
Todos os participantes da pesquisa foram informados sobre os objetivos do projeto e foi aplicado o Termo de Consentimento Livre e Esclarecido (TCLE) para os pais ou responsáveis e o Termo de Assentimento para os adolescentes em observância às normas da resolução no 196/1996 da Comissão Nacional de Ética em Pesquisa, vinculada ao Conselho Nacional de Saúde, vigente no período, assegurando-se o direito à confidencialidade, ao anonimato e à privacidade.

\section{Resultados e discussão}

Perfil dos alunos.

Responderam ao questionário 341 alunos, sendo 51\% estudantes do primeiro ano do ensino médio, $31 \%$ do segundo ano e $18 \%$ estavam cursando o último ano. A maioria estuda no período noturno, perfazendo $58,3 \%$ dos respondentes e $32 \%$ no período matutino.

Os alunos entrevistados tinham, em mediana, 16 anos no momento da pesquisa. A faixa etária variou entre 15 e 17 anos (87,5\%). 53,6\% eram do sexo feminino e $46,4 \%$ do masculino. Em relação ao quesito cor, $47,8 \%$ responderam que eram brancos, $37 \%$ mulatos e $10,8 \%$ negros.

A grande maioria dos alunos que respondeu ao questionário era solteira no momento da entrevista $(88,6 \%)$ e apenas $10,5 \%$ moravam com companheiro/a ou namorado/a. $47,5 \%$ se dizia católico, $29 \%$ declaram ser evangélico/protestante e $16 \%$ declarou não ter religião. A maioria dos entrevistados não trabalhava (70,3\%). Entre os que declararam exercer alguma atividade remunerada, aproximadamente $20 \%$ não tinham registro em carteira e trabalhavam em atividades relacionadas ao mercado informal.

Perfil da família.

Verificou-se que a renda familiar era composta por até 2 pessoas em $41 \%$ dos casos e $34 \%$ declararam que dependiam do salário de apenas um dos componentes do núcleo familiar. Nota-se que $74,3 \%$ dos respondentes afirmaram morar em casa ou apartamento próprio. O perfil familiar predominante foi do tipo nuclear. A metade dos alunos pesquisados morava com o pai, a mãe e os irmãos. As famílias chefiadas por mulheres corresponderam a $12 \%$. A escolaridade aferida dos pais revelou que a maioria 
possui apenas o ensino fundamental, sendo $47,8 \%$ para os pais e $44,9 \%$ para as mães.

Perspectiva dos alunos sobre a Orientação sexual.

A metade dos alunos que participou da pesquisa estudou a maior parte do período da educação formal de $5^{a}$ a 8 $^{a}$ série na mesma escola e $26,8 \%$ eram oriundos de outra escola da rede municipal de São Paulo. Constatou-se que $48,4 \%$ dos entrevistados estavam matriculados há pelo menos quatro anos na mesma escola. Em função do caráter retrospectivo do estudo, esse dado nos sugere que a seleção das oito escolas foi acertada, na medida em que os alunos tinham se beneficiado das ações desenvolvidas sobre o tema da sexualidade. Quando perguntado se participou alguma vez de atividade de orientação sexual oferecida na escola, 58\% responderam afirmativamente.

Nesse grupo, 73,5\% citou a aula como o tipo de atividade preponderante. Os demais citaram palestras, oficinas e outras atividades. A orientação sexual foi abordada preferencialmente nas aulas de Ciências e Biologia, conforme $59,2 \%$ das respostas. Os alunos referiram também as aulas de Educação Física e Psicologia, onde o assunto foi abordado. Os dados indicaram que esse tema foi tratado apenas duas ou três vezes durante o ano letivo. A baixa frequência do tema também foi corroborada pela questão sobre a periodicidade das aulas de orientação sexual, verificando-se que $54,8 \%$ dos alunos afirmaram que as mesmas aconteceram poucas vezes no decorrer do ano.

Para avaliar qual o enfoque dado à orientação sexual nas escolas, os estudantes receberam uma lista de assuntos relacionados à sexualidade. Essa questão permitia aos alunos assinalarem mais de uma alternativa. Os 22 itens constantes na relação procuraram abarcar um amplo leque de assuntos como gênero, respeito às diferenças, corpo, prazer, masturbação, aborto, uso de camisinha, métodos contraceptivos, entre outros. Os resultados indicaram que os assuntos mais abordados nas escolas pesquisadas em ordem decrescente foram: uso de camisinha (64\%); doenças sexualmente transmissíveis (64\%); gravidez na adolescência (62\%); HIV/Aids (58\%) e drogas (52\%). Por sua vez, o tema relações de gênero foi marcado por apenas $10 \%$ dos respondentes e 0 tema Direitos Humanos por $14 \%$. Temas considerados polêmicos como 0 aborto não foram tratados. A homossexualidade foi referida por $20 \%$ dos alunos e o tema respeito às diferenças, por 32\%. A violência sexual foi assinalada em $23 \%$ das respostas.

As palestras são, depois das aulas, uma importante atividade na informação de assuntos relacionados à orientação sexual. Constatou-se que nas escolas essas palestras têm sido realizadas no máximo cinco vezes por ano, preferencialmente ministradas por professores ou por profissionais da saúde. À semelhança do que ocorreu com as aulas, foram apontados como 
principais temas abordados o uso da camisinha (55\%), a gravidez na adolescência (53\%), o HIV/Aids (52\%), as doenças sexualmente transmissíveis (52\%) e as drogas (41\%).

Apenas $14,9 \%$ dos pais participaram de alguma atividade sobre orientação sexual realizada na escola. Os pais participaram principalmente de palestras $(6,7 \%)$. A participação de outras pessoas da comunidade superou a dos pais $(21,9 \%)$.

Segundo os respondentes, $64,7 \%$ disseram que as informações abordadas "aumentaram muito meu conhecimento sobre o assunto" e 25,8\% registraram que "aumentaram pouco meu conhecimento sobre o assunto". Apenas 9,5\% dos alunos disseram não ter acrescentado nada ao que já sabiam.

O questionário também possuía a seguinte pergunta aberta: "Qual foi a atividade sobre Orientação sexual na escola que você mais gostou? Por quê?", respondida por 223 alunos (65,3\%). Observou-se que a palestra foi a atividade mais referida, principalmente quando ministrada por profissionais de saúde ou de outra área externa à educação. Os principais temas mencionados foram: drogas, sexualidade, uso de camisinha, método contraceptivos, DST/HIV, prazer, desejo e orgasmo. Para ilustrar essas falas seguem algumas das respostas:

"As palestras, porque é interessante saber desses assuntos onde a maioria das pessoas tem vergonha de perguntar sobre suas dúvidas".

"A palestra, porque focaram melhor os assuntos e com mais clareza e na sala de aula, porque tem mais liberdade de fazer perguntas".

"Sobre orgasmo feminino e masculino e as diferenças entre o corpo da mulher e do homem. Eu achei interessante porque é legal cada um conhecer sua forma mais prazerosa até chegar ao orgasmo".

"Uso de método sexual. Porque souberam abordar muito bem o assunto. Homossexualismo, os profissionais encararam o assunto sem preconceito e com clareza suficiente".

“Discutir as diferenças sexuais, (homossexualidade, etc...), gravidez na adolescência, métodos anticoncepcionais. Aparelho reprodutor masculino/feminino. Doenças sexualmente transmissíveis etc".

"Quando foi falado do aparelho reprodutor feminino e masculino, porque são totalmente diferentes e que cada um é influenciado pelo psicológico da mulher ou do homem".

"Gravidez na adolescência, pois acho muito bom falar pra as meninas que não tem consciência e foca grávida à toa, ou muitas vezes pra segurar homem!".

"Falou sobre drogas, transmissão de doenças e comentários. Ele foi muito franco ao falar nesta palestra me emocionei demais pela forma que ele disse e até chorei e comecei a pensar mais antes de agir". 
“A única eu vi foi a minha própria apresentação de um trabalho de escola. Eu gostei porque eu aprendi mais pensando isso. E sei que meus amigos entenderam".

"Foi de um projeto que temos na escola, mas é sobre trabalhos dos próprios alunos. Foi mais interessante, pois os alunos que fizeram a apresentação eram extrovertidos e souberam falar sobre sexo sem medo".

Ao serem perguntados sobre "Qual a atividade sobre Orientação sexual na escola que você menos gostou? Por quê?", a maioria das respostas não apontou uma atividade específica, mas sim um assunto. Um dos temas muito citado foi a homossexualidade, como a seguinte resposta: "Sobre homossexualidade. Não sei me dar com o tema pois acho que o homem e a mulher foram feitos para se completar e não manter relações com ambos do mesmo sexo". Aborto, apesar de pouco abordado na escola, e gravidez na adolescência também foram lembrados:

"Sobre aborto, porque fiquei chocada com tanta frieza de algumas mulheres".

“Gravidez na adolescência, porque foi tão falado e acabou enjoando e mesmo assim não adiantou muito"

“Gravidez na adolescência, porque as meninas que ficam grávidas, ficam porque querem e não porque não tem o conhecimento...".

Em geral, os alunos não gostaram de atividades que não foram abordadas de maneira segura, clara e objetiva. Uma resposta sintetiza esse sentimento:

“[não gostei] de uma palestra que o cara falou sobre sexo como se fosse um bicho de sete cabeças. Ele não aparentava saber bem sobre o assunto tratado e não me passou segurança suficiente para eu poder acreditar no que ele dizia".

Não obstante ações relacionadas à orientação sexual tenham sido desenvolvidas nas escolas da rede municipal de São Paulo, os resultados do presente estudo evidenciam que mais de um terço dos alunos entrevistados não referiu ter participado de qualquer atividade voltada a essa temática no período da $5^{a}$ à $8^{a}$ série do Ensino Fundamental II. Entre os que se lembravam de alguma dessas atividades, a grande maioria citou a aula como atividade pedagógica preponderante, sobretudo as aulas voltadas ao ensino de Ciências, Biologia, Educação Física e Psicologia.

Esse dado revela que o enfoque pedagógico que tem sido conferido à orientação sexual pelos educadores prioriza o ponto de vista biológico e uma concepção reducionista da saúde, abordada como ausência de doenças ou distúrbios. Nesse sentido, prevalece uma concepção desatualizada e descontextualizada dos fatores que condicionam o processo de promoção da saúde e o desenvolvimento da sexualidade humana na perspectiva da integralidade dos sujeitos. O enfoque "biologizante" valoriza as dimensões do risco e da ameaça, enfatizando-se a discussão prescritiva na abordagem das doenças e dos agravos, os quais em última instância não contribuem 
para a formação de atitudes conscientes e práticas responsáveis entre os adolescentes que estão iniciando e descobrindo o exercício da sexualidade em suas vidas.

A intencionalidade na escolha, na definição e no desenvolvimento do plano de ensino adotado pelos educadores ainda está distante das diretrizes técnicas e dos pressupostos teóricos preconizados pelo Ministério da Educação para o trabalho de orientação sexual nas escolas voltado ao público adolescente. Os principais assuntos tratados nas aulas e nas palestras reiteram esse fato. Os cinco temas mais discutidos com os alunos referem-se ao uso do preservativo, às doenças sexualmente transmissíveis, a gravidez na adolescência, à infecção pelo HIV/Aids e ao uso de drogas, reiterando a relevância dada ao enfoque reducionista da prevenção de doenças e agravos ou ainda situações socialmente indesejadas.

Em síntese, a orientação sexual segue sendo uma atividade pontual, de cunho predominantemente informativo. Os dados obtidos pelo estudo não apontam para a realização de nenhuma proposta processual ou para a sondagem das necessidades e dos interesses com os alunos, embora essa perspectiva tenha sido discutida nas ações de formação conduzidas pelos programas de orientação sexual executados com os profissionais da rede de ensino. A ideia de que as escolas deve contribuir para a promoção do senso de auto-responsabilidade e de compromisso com a própria saúde e sexualidade, ao lado da defesa da não violência e da não discriminação sexual, não parece ter ganhado maior relevância para interações dos jovens dentro e fora das escolas. Os dados obtidos junto aos alunos, ao contrário, indicam que eles assumem e reproduzem a visão preponderante sobre a orientação sexual, justificada pelas doenças sexualmente transmissíveis e pela gravidez na adolescência.

A sexualidade não foi tratada de forma articulada com os projetos de vida dos jovens, o que certamente não os protege dos riscos envolvidos na atividade sexual cercada de tabus e proibições. Temas como gênero, direitos humanos, respeito às diferenças e à diversidade, convivência pacífica entre homens e mulheres, não violência, entre outros, quase não foram apontados pelos alunos. Questões como homossexualidade e aborto também seguem invisibilizados.

O modelo adotado é restrito a palestras realizadas por profissionais de saúde ou a aulas de Ciências e de Biologia. Nota-se, por outro lado, que a orientação sexual não deve oferecer respostas prontas, mas problematizar junto com os alunos, inserindo a sexualidade num projeto de vida. Essa perspectiva é favorecida com a adoção de dinâmicas de grupo, jogos ou dramatizações, que podem ser inseridas em diversos contextos de aprendizagem independentemente das matérias ligadas à Biologia. Possivelmente, os professores não se sentem respaldados para um trabalho de cunho processual, construtivista e interdisciplinar. Jardim \& Brêtas (2006) indicam que os professores tem mais facilidade em utilizar conhecimentos relacionados ao desenvolvimento físico e biológico dos adolescentes do que discutir as vivências e as experiências deste momento da vida. Os dados 
obtidos no estudo apontam que essa situação se manteve presente nas escolas, sendo reproduzida nas respostas dos alunos.

É importante frisar que a abordagem da sexualidade não pode se esgotar na transmissão de conteúdos técnicos, porque as informações isoladamente não contribuem para aumentar a percepção das atitudes de risco e a mudança de comportamentos vulneráveis socialmente construídos. De acordo com os alunos as palestras ocorreram na frequência de cinco vezes ao ano, restringindo-se, portanto, a atividades pontuais e desarticuladas de uma proposta coletiva e interdisciplinar coordenada pelos professores. Essa estratégia não permite a construção de vínculos de confiança e acolhimento na relação com os alunos que são elementos essenciais para a discussão da sexualidade nos seus diferentes aspectos.

Estudos também indicam que as abordagens que associam a oferta de informação por meio de palestras, com distribuição de folders e demonstração do uso do preservativo, ainda é uma prática hegemônica nas escolas, perpetuando-se um modelo campanhista, adotado desde o inicio do século passado pela saúde pública no país. (Paiva et al., 2006). Em suma, o convite para os profissionais da saúde ministrarem palestras, quando desarticuladas de um projeto executado em parceria, no qual interesses e saberes conjuntos são compartilhados, acabam se tornando oportunidades perdidas que não contribuem para a assunção do papel profissional dos educadores no próprio lócus da escola. Perde-se também a possibilidade de estreitar laços e interfaces na articulação com a rede municipal de saúde para a promoção da saúde integral dos adolescentes.

Ao lado da baixa frequência com que essas atividades ocorreram, a pouca participação dos pais e da comunidade em atividades relacionas à orientação sexual também é reveladora da ausência desse tema nas escolas. Não obstante seja um dos pilares dos programas de capacitação incentivar a participação dos pais e promover atividades continuadas, isso ainda não se tornou uma realidade nas escolas. Assim, permanecem lacunas e desafios programáticos a serem enfrentados pelas equipes das escolas na abordagem da temática da orientação sexual, a exemplo da inserção do tema no projeto político-pedagógico, do investimento em propostas de formação e capacitação permanentes dos professores, associadas a supervisão técnico-pedagógica e ao fortalecimento do trabalho interdisciplinar.

Não obstante essas dificuldades, observa-se uma grande aceitação do tema pelos alunos superior a $65 \%$ das respostas aferidas. Ressalta-se que, nas falas citadas, percebe-se que os alunos sentem a necessidade de debater e ter informações sobre diversas situações que envolvem a sexualidade e a saúde.

\section{Considerações Finais}


O presente artigo investigou, através de uma pesquisa com estudantes, - limite e as possibilidades para a implantação da Orientação sexual nas escolas, em consonância com os marcos dos direitos sexuais e reprodutivos e com uma visão mais abrangente da sexualidade, para além dos dispositivos de disciplinarização dos corpos. Observou-se a reprodução de um padrão baseado na prevenção das doenças sexualmente transmissíveis e da gravidez na adolescência, através de atividades pontuais e predominantemente informativas. Praticamente não se encontra referência a continuidade de um projeto, onde os temas ligados à sexualidade emerjam das situações vividas pelos estudantes e possam ser articuladas aos seus projetos de vida. Ao contrário, o foco das ações esteve centrado numa visão biologizante e restritiva da sexualidade. Temas como a homossexualidade e o aborto estiveram pouco presentes nas atividades.

Embora a temática da orientação sexual tenha permanecido durante os cinco anos do período compreendido pelo presente estudo (2001 a 2005) no universo das escolas estudadas, as respostas dos alunos revelam que os resultados alcançados pelos programas foram limitados. É possível que a falta de um planejamento estratégico nas Secretarias Municipais da Educação e da Saúde voltado a questão da orientação sexual tenha contribuído para a descontinuidade e fragmentação das ações no âmbito das escolas. Embora exista o reconhecimento da importância da orientação sexual e uma sensibilidade para a necessidade de uma abordagem continuada e aprofundada desse tema, as escolas continuam realizando atividades pontuais, focadas em informações, o que não possibilita a formação do corpo docente para o tratamento das diferentes questões da sexualidade. Os profissionais da educação sentem-se com pouco poder, legitimidade e profundidade para atuarem, o que, em parte, deve-se à descontinuidade dos projetos.

As dificuldades dos profissionais podem ser atribuídas a fatores pessoais, à falta de capacitação e a fatores institucionais, marcados por políticas públicas insuficientes para a sustentação dessa temática no ambiente escolar. No presente estudo, constatamos que o despreparo produz condutas discriminatórias e pouco reflexivas, o que contribui para a imposição de valores, mitos e crenças na orientação sexual.

Transformar uma plataforma de orientação sexual em pauta para as políticas públicas prossegue sendo um grande desafio para a escola e para a sociedade. Embora tenha ocorrido um avanço no reconhecimento dos direitos sexuais e reprodutivos como Direitos Humanos, muito ainda há que se avançar 
neste sentido. Sobretudo para a construção de um projeto de advocacy para os adolescentes, nas áreas da educação e da saúde. É imprescindível a criação de uma rede social e política de apoio contínuo às ações desenvolvidas pelas escolas.

A orientação sexual é um campo de saberes e de práticas essencial para a construção de uma sociedade mais justa e equânime, onde a saúde sexual e reprodutiva possa ser desfrutada desde a infância e os projetos de vida, nas diversas gerações, tenham a oportunidade de se realizar. Em consonância com as afirmações de outros especialistas no tema, como Silva \& Megid Neto (2006, p.187), concluímos que “...a não obrigatoriedade dos PCN, associada à tendência ao conservadorismo e à estagnação que a escola está sujeita, como qualquer outra instituição social, torna possível que a implantação da Educação Sexual continue restrita apenas a algumas experiências isoladas". Para que a orientação sexual venha a se tornar uma política consistente, em consonância aos Direitos Humanos, é preciso envidar esforços dos gestores para o aprimoramento das articulações intersetoriais e para a institucionalização das ações. Do mesmo modo, a sociedade civil e os conselhos das áreas envolvidas possuem um papel fundamental no controle social dessa política.

\section{Referências Bibliográficas}

Altmann, Helena. (2001). Orientação sexual nos Parâmetros Curriculares Nacionais. Revista Estudos Feministas, 9(2), 575-585.

Arilha, Margareth \& Calazans, Gabriela. (1998). Sexualidade na adolescência: o que há de novo? Em Comissão Nacional de População e Desenvolvimento (CNPD). Jovens acontecendo na trilha das políticas públicas. Brasília: CNPD.

Ávila, Maria Bethânia \& Corrêa, Sônia. (1999). O movimento de saúde e direitos reprodutivos no Brasil: revisitando percursos. Em Galvão, L. \& Díaz J. (Org.). Saúde sexual e reprodutiva no Brasil. São Paulo: Hucitec; Population Council.

Fonseca, Jairo Simon da \& Martins, Gilberto de Andrade. (1996). Curso de estatística. São Paulo: Atlas.

Galvão, Loren \& Díaz, Juan. (org.). (1999). Saúde Sexual e Reprodutiva no Brasil: dilemas e desafios. São Paulo: Hucitec. 
Inojosa, Rose Marie. (1998). Intersetorialidade e a configuração de um novo paradigma organizacional. Revista de Administração Pública, 32(2), 35-48.

Jardim, Dulcilene Pereira \& Brêtas, José Roberto da Silva. (2006). Orientação sexual na escola: a concepção dos professores de Jandira - SP. Rev Bras Enferm, 59 (2), 157-162.

Junqueira, Rogério D. (2009). "Aqui não temos gays nem lésbicas": estratégias discursivas de agentes públicos ante medidas de promoção do reconhecimento da diversidade sexual nas escolas. Bagoas, 3(4), 171-189.

Lei no 8069, de 13 de julho de 1990. Dispõe sobre o Estatuto da Criança e do Adolescente e dá outras providências. Diário Oficial da União, seção 1.

Lei no 9.394, de 20 de dezembro de 1996. Estabelece as diretrizes e bases da educação nacional. Diário Oficial da União, seção 1.

Lei no 10.172, de 9 de janeiro de 2001. Aprova o Plano Nacional de Educação e dá outras providências. Diário Oficial da União, seção 1.

Levin, Jack. (1987). Estatística aplicada às Ciências Humanas. São Paulo: Harbra.

Louro, Guacira Lopes. (2004). Gênero, sexualidade e educação. Petrópolis: Vozes.

Ministério da Educação e do Desporto. Secretaria de Educação Fundamental. (1997). Parâmetros Curriculares Nacionais: introdução aos parâmetros curriculares nacionais. Brasília: Ministério da Educação e do Desporto.

Ministério da Saúde. (2005). Marco legal: saúde, um direito de adolescentes. Série A. Normas e Manuais Técnicos. Brasília: Ministério da Saúde.

Nações Unidas (1994). Relatório da Conferência Internacional sobre população e Desenvolvimento - Plataforma de Cairo. Disponível na internet em: http://www.unfpa.org.br/Arquivos/relatorio-cairo.pdf [Data de acesso: 22 jan. 2015].

Paiva, Vera., Pupo, Ligia R., \& Barboza, Renato. (2006). O direito à prevenção e os desafios da redução da vulnerabilidade ao HIV no Brasil. Revista de Saúde Pública, 40(Supl), 109-119.

Pirotta, Wilson R.B., \& Pirotta, Kátia C. M. (1999). O adolescente e o direito à saúde após a Constituição de 1988. Em Schor, Néia; Mota, M.S.F.T.; Branco, V.C. (Org.). Cadernos Juventude, saúde e desenvolvimento. Brasília: Ministério da Saúde, Secretaria de Políticas de Saúde.

Pirotta, Wilson R. B. \& Pirotta, Kátia C. M. (2005). Relações de gênero e poder: os adolescentes e os direitos sexuais e reprodutivos no Estatuto da Criança e do Adolescente. Em Rubens de Camargo Ferreira Adorno, Augusta Thereza de Alvarenga, Maria da Penha Costa Vasconcellos. (Org.). Jovens, trajetórias, masculinidades e direitos. São Paulo: EDUSP.

Pirotta, Katia C. Machado,. Pupo, Lígia R., Barboza, Renato,. Unbehaum, Sandra., \& Cavasin, Sylvia. (2006). Educação Sexual na Escola e Direitos 
Sexuais e Reprodutivos - Avaliação da Política da Secretaria Municipal de Educação de São Paulo 2001 a 2005. Relatório final de pesquisa. Ecos Comunicação em Sexualidade/Instituto de Saúde.

Pitanguy, Jacqueline. (1999). O movimento nacional e internacional de saúde e direitos reprodutivos. Em Giffin, Karen; Costa, Sarah Hawker (Org.). Questões da saúde reprodutiva. Rio de Janeiro: Ed. Fiocruz.

Silva, Regina Célia Pinheiro da \& Megid Neto, Jorge. (2006). Formação de professores e educadores para abordagem da educação sexual na escola: o que mostram as pesquisas. Ciência \& Educação, 12(2), 185-197.

United Nations. (1995). The Fourth World Conference on Women - Beijing Declaration and Platform for Action. Disponível na internet em: http://www.un.org/womenwatch/daw/beijing/pdf/BDPfA\%20E.pdf [Data de acesso: 22 jan. 2015].

Vianna, Claudia P., \& Unbehaum, Sandra. (2004). O gênero nas políticas públicas de educação no Brasil: 1988-2002. Cadernos de Pesquisa, 34(121), 77-104.

Recebido em 12/02/2013

Aceito em 08/06/2013. 